\title{
Comparison of two standardized methods of methacholine inhalation challenge in young adults
}

\author{
H.C. Siersted*, C.M. Walker*, A.D. O'Shaughnessy*, A.R. Willan", E.M. Wiecek", M.R. Sears*
}

Comparison of two standardized methods of methacholine inhalation challenge in young adults. H.C. Siersted, C.M. Walker, A.D. O'Shaughnessy, A.R. Willan, E.M. Wiecek, M.R. Sears. C) ERS Journals Ltd 2000.

ABSTRACT: In the European Community Respiratory Health Study (ECRHS), airway responsiveness to methacholine was determined using the Mefar dosimeter protocol. Elsewhere, the 2-min tidal breathing method has become the preferred standardized method. The relationship between measurements of responsiveness by these two methods is not well established.

This study measured airway responsiveness to methacholine by dosimeter and tidal breathing methods in 47 healthy asthmatic subjects aged $20-44$ yrs. Tests were performed within 1 week and in random order.

Baseline forced expiratory volume in one second (FEV1) varied by $<\mathbf{1 0 \%}$ between tests in 42/47 subjects. There was a close association between responsiveness determined by the two methods. A provocative concentration of methacholine causing a $20 \%$ fall in FEV1 (PC20) value of $\leq 8.0 \mathrm{mg} \cdot \mathrm{mL}^{-1}$ (tidal method) used to categorize airway hyperresponsiveness agreed most closely with a provocative dose of methacholine causing a $20 \%$ fall in FEV1 (PD20) value of $\leq 0.5 \mathrm{mg}$ (dosimeter method) (kappa statistic 0.78). Each doubling or halving of PC20 to define a level of hyperresponsiveness agreed closely with a doubling or halving of PD20.

Assessment of airway responsiveness as provocative dose of methacholine causing a $\mathbf{2 0 \%}$ fall in forced expiratory volume in one second by the Mefar dosimeter protocol gave a close and predictable relationship with provocative concentration of methacholine causing a $\mathbf{2 0} \%$ fall in expiratory volume in one second assessed using the tidal breathing method. Airway hyperresponsiveness as determined by the accepted criterion of provocative concentration of methacholine causing a $20 \%$ fall in expiratory volume in one second $\leq 8 \mathrm{mg} \cdot \mathrm{mL}^{-1}$ was best correlated with provocative dose of methacholine causing a $20 \%$ fall in forced expiratory volume in one second $<0.5 \mathrm{mg}$ by Mefar dosimeter.

Eur Respir J 2000; 15: 181-184.

Measurements of airway responsiveness are well established in diagnosis and assessment of asthma, both in clinical practice and in studies of population epidemiology [1-3]. In the European Community Respiratory Health Survey (ECRHS), conducted in European Union countries and in many other countries worldwide [4], airway responsiveness was measured by methacholine inhalation challenge using the Mefar dosimeter protocol [5]. Six Canadian centres participated in this study, and all used the Mefar. dosimeter (MB3; Mefar, Boverro, Italy). However, for many years Canadian laboratories and many others worldwide have used a different method to measure airway responsiveness, involving 2 min of tidal breathing of methacholine in incremental concentrations delivered via Wright nebulizers [6]. The authors wished to establish the relationship between determinations of airway responsiveness by these two methods in this population.

\section{Methods}

\section{Subjects}

As the ECRHS was conducted among adults aged 20$44 \mathrm{yrs}$, this age range was selected for study. Subjects
Depts of *Medicine and ${ }^{*}$ Clinical Epidemiology and Biostatistics, McMaster University, Hamilton, Ontario, Canada.

Correspondence: M.R. Sears

Firestone Regional Chest \& Allergy Unit St. Joseph's Hospital

50 Chariton Avenue East

Hamilton

Ontario L8N 4A6

Canada

Fax: 019055216132

Keywords: Airway hyperresponsiveness asthma

epidemiology

methods

Received: March 11999

Accepted after revision August 121999 undergoing methacholine challenge for clinical evaluation of suspected asthma $(n=8)$, subjects with established asthma $(n=30)$ and healthy subjects expected to have minimal or no responsiveness to methacholine $(n=9)$, were recruited from the outpatient clinics, hospital and research laboratory staff. The study was approved by the Research Committee, St. Joseph's Hospital, Hamilton, Ontario, Canada. All subjects provided written consent.

\section{Lung function}

Spirometry was recorded using a rolling seal Spirotech Spirometer (Graseby Andersen, Atlanta, GA, USA) for the dosimeter protocol, while for the tidal breathing protocol, spirometry was recorded on a Koko Trek pneumotachygraph-based computerized spirometer (Pulmonary Data Service Instruments, Louisville, KY, USA). At least three acceptable forced expiratory volume in one second (FEV1) and forced vital capacity (FVC) measurements were recorded, in accordance with American Thoracic Society standards. Both spirometers were calibrated daily with the same $3 \mathrm{~L}$ syringe. 


\section{Methacholine challenge protocols}

Both tests were performed within 1 week, in randomized order. Subjects had to be stable with no recent known allergen exposure, no respiratory tract infection, and no change in medication or in other circumstances which could influence airway responsiveness.

\section{Mefar dosimeter}

Methacholine solutions were prepared in concentrations of $0.39,1.56,6.25$ and $12.5 \mathrm{mg} \cdot \mathrm{mL}^{-1}$ in normal saline, using acetyl- $\beta$-methylcholine chloride powder. Mefar nebulizers (MB3; Mefar) calibrated to an output of $0.010 \mathrm{~mL}$ per inhalation were used to administer saline or methacholine [5]. After recording baseline FEV1 the subject inhaled three breaths of normal saline, and FEV1 was measured after $60 \mathrm{~s}$. If FEV 1 decreased $>10 \%$ after saline, testing was discontinued, otherwise the subject followed either a short or long protocol for methacholine challenge (table 1). Both protocols provided the same total cumulative dose, delivered in nine steps in the long protocol and five in the short protocol. The long protocol was used if subjects had a history of wheezing, attacks of shortness of breath, trouble with breathing in the last 12 months, had woken up with tightness of chest or an attack of shortness of breath in the last 12 months, or reported ever having asthma. The short protocol was used for subjects not reporting any relevant respiratory history. FEV1 was measured $60 \mathrm{~s}$ following each dose, and unless there was a $20 \%$ decrease in FEV1, the subject proceeded to inhale the next concentration of methacholine. If a subject commenced the short protocol, this was changed to the long protocol if FEV 1 fell by $>10 \%$. Testing was stopped when FEV1 fell by $\geq 20 \%$ of the post saline FEV1, or when the final dose had been given according to the protocol (table 1). The cumulative dose of methacholine required to produce a $20 \%$ fall in FEV1 from the post saline FEV1 (PD20) was calculated by interpolation. A bronchodilator was administered at the end of the procedure to ensure that the subject's FEV1 returned to within $10 \%$ of the post saline FEV1.

\section{Tidal breathing method}

Methacholine challenge was performed according to the protocol of COCKCROFT et al. [6], preceded by 15 min rest. Following baseline spirometry, FEV1 was remeasured after inhalation of normal saline for $2 \mathrm{~min}$, followed by doubling concentrations of methacholine solutions in normal saline in concentrations from $0.03-16 \mathrm{mg} \cdot \mathrm{mL}^{-1}$. The aerosols were generated by a Wright nebulizer (Bay View Medical and Home Care, Baltimore, MD, USA; output calibrated to $0.13 \mathrm{mg} \cdot \mathrm{mL}^{-1}$ ) and inhaled by tidal breathing for 2 min with the nose clipped. FEV1 was measured at $30 \mathrm{~s}$ and $90 \mathrm{~s}$ after each dose. If the FEV1 was lower at $90 \mathrm{~s}$ than at $30 \mathrm{~s}$, additional measurements were made at $180 \mathrm{~s}$ and every 2 min thereafter until the lowest FEV1 was determined. Subsequent concentrations were given at $\sim 5$ min intervals until the FEV1 decreased $\geq 20 \%$ from the lowest post saline FEV1, or until the highest concentration had been given. The provocative concentration of methacholine required to produce a $20 \%$ fall in FEV1 from the post saline FEV1 (PC20) was calculated by interpolation. Once the FEV1 stopped failing after the last inhalation, the subject was given salbutamol to reverse the bronchoconstriction.

\section{Analysis}

The overall agreement was examined by determining the Spearman correlation coefficient between the two measures of airway responsiveness. Additionally, the per cent agreement and kappa statistic for agreement (which takes into account the likelihood of chance agreement) were calculated for each cut-point for PC20 $(0.5,1.0,2.0,4.0$, 8.0 and $16.0 \mathrm{mg} \cdot \mathrm{mL}^{-1}$ ) in relation to cut-points for PD20 $(0.0312,0.0625,0.125,0.25,0.5,1.0$ and $2.0 \mathrm{mg})$.

\section{Results}

Baseline FEV1 was similar in both tests (Mefar (MB3; Mefar) baseline FEV1 $102.5 \%$ of tidal method baseline FEV1, SD 5.3\%). All except three subjects had baseline FEV $1>80 \%$ predicted on both tests, the exceptions having values of $78 \%$ and $80 \%, 77 \%$ and $86 \%$, and $78 \%$ and $86 \%$ respectively. The FEV1 differed at baseline by $>10 \%$ in only five subjects (range 10.1-17.8\%).

Technically satisfactory methacholine challenges with both methods were obtained in all 47 subjects. Of these, eight subjects were nonresponsive and did not achieve a $20 \%$ fall in FEV1 with either method, two subjects achieved $\geq 20 \%$ fall with the Mefar (MB3; Mefar) method but not with the tidal breathing method, five subjects achieved $\geq 20 \%$ fall with the tidal breathing method but not the Mefar (MB3; Mefar) method, while 32 subjects achieved $\geq 20 \%$ fall with both methods (fig. 1).

Table 1. - Dose schedules for the short and long protocols for methacholine inhalation by Mefar dosimeter*

\begin{tabular}{|c|c|c|c|c|c|c|c|c|c|}
\hline \multicolumn{5}{|c|}{ Short protocol } & \multicolumn{5}{|c|}{ Long protocol } \\
\hline Step & $\begin{array}{c}\text { Concentration } \\
\mathrm{mg} \cdot \mathrm{mL}^{-1}\end{array}$ & Breaths & $\begin{array}{l}\text { Dose } \\
\mathrm{mg}\end{array}$ & $\begin{array}{l}\text { Cumulative } \\
\text { dose mg }\end{array}$ & Step & $\begin{array}{c}\text { Concentration } \\
\mathrm{mg} \cdot \mathrm{mL}^{-1}\end{array}$ & Breaths & $\begin{array}{l}\text { Dose } \\
\text { mg }\end{array}$ & $\begin{array}{l}\text { Cumulative } \\
\text { dose mg }\end{array}$ \\
\hline \multirow{3}{*}{1} & & & & & 1 & 0.39 & 2 & 0.0078 & 0.0078 \\
\hline & 0.39 & 4 & 0.0156 & 0.0156 & 2 & 0.39 & 2 & 0.0078 & 0.0156 \\
\hline & & & & & 3 & 1.56 & 1 & 0.0156 & 0.0312 \\
\hline \multirow[t]{2}{*}{2} & 1.56 & 3 & 0.0468 & 0.0625 & 4 & 1.56 & 2 & 0.0312 & 0.0625 \\
\hline & & & & & 5 & 6.25 & 1 & 0.0625 & 0.125 \\
\hline \multirow[t]{2}{*}{3} & 6.25 & 3 & 0.1875 & 0.25 & 6 & 6.25 & 2 & 0.25 & 0.25 \\
\hline & & & & & 7 & 12.5 & 2 & 0.250 & 0.5 \\
\hline 4 & 12.5 & 6 & 0.750 & 1.0 & 8 & 12.5 & 4 & 0.500 & 1.0 \\
\hline 5 & 12.5 & 8 & 1.0 & 2.0 & 9 & 12.5 & 8 & 1.0 & 2.0 \\
\hline
\end{tabular}

*: MB3; Mefar, Boverro, Italy. 

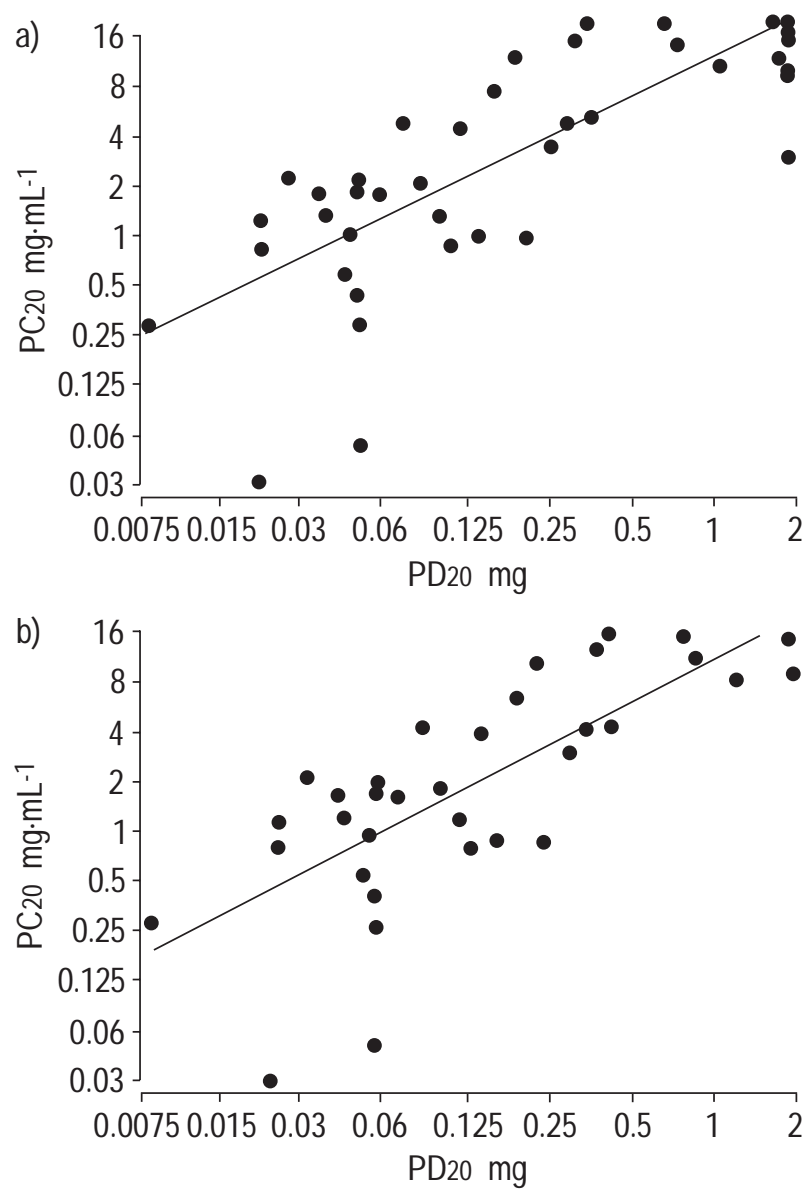

Fig. 1. - a) Distribution of provocative concentration of methacholine causing a $20 \%$ fall in forced expiratory volume in one second (FEV1) (PC20) and provocative dose of methacholine causing a $20 \%$ fall in forced expiratory volume in one second (FEV1) (PD20) values in 47 subjects. The regression line was calculated using all data points, including those 15 outside the range of measurement $\left(\mathrm{PC}_{20}>16 \mathrm{mg}\right.$. $\mathrm{mL}^{-1}$, considered to be $16 \mathrm{mg} \cdot \mathrm{mL}^{-1}(\mathrm{n}=10)$, and PD20 $>2 \mathrm{mg}$, considered to be $2 \mathrm{mg} \cdot \mathrm{mL}^{-1},\left(\mathrm{n}=13\right.$, including eight with $\left.\mathrm{PC} 20>16 \mathrm{mg} \cdot \mathrm{mL}^{-1}\right)$; $\mathrm{rS}=0.84$. b) Distribution of $\mathrm{PC} 20$ and PD20 values in 32 subjects with $\mathrm{PC} 20 \leq 16 \mathrm{mg} \cdot \mathrm{mL}^{-1}$ and $\mathrm{PD} 20 \leq 2 \mathrm{mg}$. The regression line was calculated using only subjects with data within the range of measurement; $r S=0.75$.

The correlation between the tests was high (Spearman coefficient $0.840, \mathrm{p}<0.00005)$. At the usually accepted cutpoint for a positive test of $\leq 8 \mathrm{mg} \cdot \mathrm{mL}^{-1}$ for the tidal breathing method, 28/47 subjects were "hyperresponsive", of whom 26 had PD20 $\leq 0.5 \mathrm{mg}$ (table 2). Hence a PD20 value of $0.5 \mathrm{mg}$ provided the closest categorical agreement to a PC20 of $8 \mathrm{mg} \cdot \mathrm{mL}^{-1}(89.4 \%)$. Similarly, using a cut-point of $\mathrm{PC} 20 \leq 4 \mathrm{mg} \cdot \mathrm{mL}^{-1}, 23$ subjects were "hyperresponsive", of whom 21 had $\mathrm{PD} 20 \leq 0.25 \mathrm{mg}$. The association between tests was established using the PD20 cut-points with the highest kappa statistic for each PC20 (table 3). Each doubling or halving of PC20 cut-point for categorizing "hyperresponsiveness" was associated with a doubling or halving of the PD20 cut-point providing the highest kappa statistic and highest per cent agreement, suggesting a linear relationship between doubling doses of PD20 and doubling concentrations of PC20.

Over the range $1.0-16.0 \mathrm{mg} \cdot \mathrm{mL}^{-1}$, kappa statistic and per cent agreement were maximal at the same cut-points,
Table 2. - Distribution of "positive" and "negative" results for airway hyperresponsiveness

\begin{tabular}{lccc}
\hline & \multicolumn{3}{c}{ PD20 $(\mathrm{mg})$} \\
\cline { 2 - 4 } PC20 $\mathrm{mg} \cdot \mathrm{mL}^{-1}$ & 0.5 & $>0.5$ & Total \\
\hline$\leq 8$ & 26 & 2 & 28 \\
$>8$ & 3 & 16 & 19 \\
Total & 29 & 18 & 47
\end{tabular}

The results were categorized by a provocative dose of methacholine causing a $20 \%$ fall in forced expiratory volume in one second $(\mathrm{FEV} 1)(\mathrm{PC} 20) \leq 8 \mathrm{mg} \cdot \mathrm{mL}^{-1}$ and a provocative dose of methacholine causing a $20 \%$ fall in FEV1 (PD20) $\leq 0.5 \mathrm{mg}$. Per cent agreement $=(26+16) / 47=89.4 \%$. Kappa statistic $=0.78$.

with highest values for both measures of agreement occurring within the range of PC20 $2.0-8.0 \mathrm{mg} \cdot \mathrm{mL}^{-1}$ (PD20 $0.125-0.5 \mathrm{mg})$.

\section{Discussion}

A number of methods of determining airway responsiveness by histamine or methacholine challenge have been reported, but the most widely used in North America and many other countries is the tidal breathing method described by CocKCROFT et al. [6]. However, for the purpose of standardization with other countries, the Mefar dosimeter (MB3; Mefar) method was used for the North American component of the international ECRHS study [4]. The current study has shown a strong categorical relationship between results obtained by the two methods in young adults. The usually accepted cut-point for the tidal breathing method for defining airway hyperresponsiveness of $\leq 8 \mathrm{mg} \cdot \mathrm{mL}^{-1}$ was best reflected in a PD20 value $\leq 0.5 \mathrm{mg}$, and the more clearly asthmatic range of responsiveness with $\mathrm{PC}_{20} \leq 4 \mathrm{mg} \cdot \mathrm{mL}^{-1}$ reflected in PD20 $\leq 0.25 \mathrm{mg}$. The relationship between the two methods was maintained through each doubling dose or concentration.

The level of agreement between the respective PD20 and PC20 values was high. As quoted by AlTMAN [7], kappa $>0.4$ represents moderate agreement, and kappa $>0.6$

Table 3. - Comparison between optimum cut-points for agreement between the dosimeter and tidal breathing methods

\begin{tabular}{llcc}
\hline $\begin{array}{l}\mathrm{PC} 20 \\
\mathrm{mg} \cdot \mathrm{mL}^{-1}\end{array}$ & $\begin{array}{c}\mathrm{PD} 20 \\
\mathrm{mg}\end{array}$ & $\begin{array}{c}\text { Agreement } \\
\%\end{array}$ & $\begin{array}{c}\text { Kappa } \\
\text { statistic }\end{array}$ \\
\hline$\leq 0.5$ & $\leq 0.0625$ & 78.7 & 0.405 \\
$\leq 1.0$ & $\leq 0.0625$ & 78.7 & 0.473 \\
$\leq 2.0$ & $\leq 0.125$ & 91.5 & 0.823 \\
$\leq 4.0$ & $\leq 0.25$ & 89.4 & 0.787 \\
$\leq 8.0$ & $\leq 0.5$ & 89.4 & 0.777 \\
$\leq 16.0$ & $\leq 1.0$ & 85.1 & 0.624 \\
\hline
\end{tabular}

Optimum cut-points of provocative dose of methacholine causing a $20 \%$ fall in forced expiratory volume in one second (FEV1) (PD20) for maximal per cent agreement and kappa statistic for agreement between dosimeter and tidal breathing methods at different cut-points of provocative concentration of methacholine causing a $20 \%$ fall in FEV1 (PC20) from $\leq 0.5$ $\leq 16 \mathrm{mg} \cdot \mathrm{mL}^{-1}$ to define degree of airway hyperresponsiveness to methacholine. 
good agreement. In the current study, the kappa statistic at each cut-point ranged $0.41-0.82$, and was $0.78-0.82$ over the range of $\mathrm{PC} 202.0-8.0 \mathrm{mg} \cdot \mathrm{mL}^{-1}$.

One requirement for repeatabillity of airway challenge testing is similar baseline calibre [3]. Some authors have excluded those with $>10 \%$ difference in baseline FEV1 from analysis [8]. Among the current 47 paired methacholine challenges, FEV 1 differed at baseline by $>10 \%$ in only five subjects. The authors analysed the data including and excluding those subjects, with no substantive difference in the results. Including all 47 subjects, overall correlation was 0.840 , while after excluding the subjects with $>10 \%$ variability in baseline, correlation was 0.864 .

Previous studies have compared other methods of performing methacholine challenge tests in adults and children. YAN et al. [9] found a close agreement between PD20 values determined by a dosimeter method and the hand held deVilbiss nebulizer. SEARs et al. [10] showed a close agreement between a short five breath method of performing methacholine challenge modified from $\mathrm{CHAI}$ et al. [11] and the 2 min tidal breathing method in New Zealand children [10]. Снатнам et al. [8] used an abbreviated five breath method with only two methacholine concentrations in children with a history of wheezing, or only one concentration $\left(25 \mathrm{mg} \cdot \mathrm{mL}^{-1}\right)$ in subjects without wheezing, and found high correlations with the longer protocol by rank order analysis ( 0.94 for the whole group, and 0.77 in asthmatics). On the other hand, AsHER et al. [12] tested 30 children, 19 with known or suspected asthma, and showed that a five breath method utilizing inspiratory capacity breaths of methacholine gave a lower rate of airway responsiveness positivity than the $2 \mathrm{~min}$ tidal breathing method, $68 \%$ versus $95 \%$ respectively of the likely asthmatic children showing airway responsiveness to each method.

Repeatability of methacholine challenges using identical methods under very strictly controlled conditions at a short interval is very high [13]. In studies where the same provoking agent has been used, and the duration of inhalation or frequency of dosing adjusted, shorter and longer methods have generally given quite comparable results [14]. A high level of agreement is obtained even using different methods and different challenge agents, e.g. comparing histamine by the short YAN et al. [9] protocol with methacholine inhalation using a Mefar (MB3; Mefar) dosimeter [15]. In that study the agreement defined by kappa at the final dose cut-point was 0.79 (95\% confidence interval $0.60-0.98$ ) while the percentage of tests in agreement was $89 \%$ and the average correct classification $94 \%$.

In conclusion, this study has shown that there is a very close association between categories of airway responsiveness determined by the Mefar dosimeter (MB3; Mefar) method and the tidal breathing method, and that hyperresponsiveness defined as provocative dose of methacholine causing a $20 \%$ fall in forced expiratory volume in one second $\leq 0.5 \mathrm{mg}$ by dosimeter most closely agrees with a provocative concentration of methacholine causing a $20 \%$ fall in forced expiratory volume in one second of $\leq 8.0$ $\mathrm{mg} \cdot \mathrm{mL}^{-1}$. These data will enhance the accuracy of comparisons of prevalence of hyperresponsiveness between studies using these different methods.

\section{References}

1. Nowak D, Heinrich J, Jorres R, et al. Prevalence of respiratory systems, bronchial hyperresponsiveness and atopy among adults: West and East Germany. Eur Respir $J$ 1996; 9: 2541-2552.

2. Siersted HQ, Mostgaard G, Hyldebrandt N, Hansen HS, Boldsen J, Oxhoj H. Interrelationships between diagnosed asthma, asthma-like symptoms and abnormal airway behaviour in adolescence: the Odense Schoolchild Study. Thorax 1996; 51: 503-509.

3. Britton J, Pavord I, Richards K, et al. Factors influencing the occurrence of airway hyperreactivity in the general population: the importance of atopy and airway calibre. Eur Respir J 1994; 7: 881-887.

4. Burney P. Asthma prevalence and risk factors. In: Vuylsteek K, Hallen M, eds. Epidemiology. Amsterdam, IOS press, 1994; pp. 241-251.

5. Chinn S, Burney P, Jarvis D, Luczynska C, on behalf of the European Community Respiratory Health Survey (ECRHS). Variation in bronchial responsiveness in the European Community Respiratory Health Survey (ECRHS). Eur Respir J 1997; 10: 2495-2501.

6. Cockcroft DW, Killian DN, Mellon JA, Hargreave FE. Bronchial reactivity to inhaled histamine: a method and clinical survey. Clin Allergy 1977; 7: 235-243.

7. Altman DG. Practical statistics for medical research. 1st Edn. London, Chapman and Hall, 1991; p. 404.

8. Chatham M, Bleecker ER, Norman P, Smith PL, Mason P. A screening test for airways reactivity. An abbreviated methacholine inhalation challenge. Chest 1982; 82: 15-18.

9. Yan K, Salome Q, Woolcock AJ. Rapid method for measurement of bronchial responsiveness. Thorax 1983; 38: 760-765.

10. Sears MR, Jones DT, Holdaway MD, et al. Prevalence of bronchial reactivity to inhaled methacholine in New Zealand children. Thorax 1986; 41: 283-289.

11. Chai H, Farr RS, Froehlich LA, et al. Standardisation of bronchial inhalation challenge procedures. J Allergy Clin Immunol 1997; 56: 323-327.

12. Asher ME, Bertrand JM, Beaudry PH, Coates AL. Histamine inhalation challenge in children: a comparison of two methods. Ann Allergy 1983; 50: 389-392.

13. Juniper EF, Frith PA, Dunnet C, Cockcroft DW, Hargreave FE. Reproducibility and comparison of responses to inhaled histamine and methacholine. Thorax 1978; 33: 705-710.

14. Jorres RA, Nowak D, Kirsten D, Gronke L, Magnusson H. A short protocol for methacholine provocation testing adapted to the Rosenthal-Chai dosimeter technique. Chest 1997; 111: 866-869.

15. Toelle BG, Peat JK, Salome CM, et al. Comparison of two epidemiological protocols for measuring airway responsiveness and allergic sensitivity in adults. Eur Respir J 1994; 7: 1798-1804. 